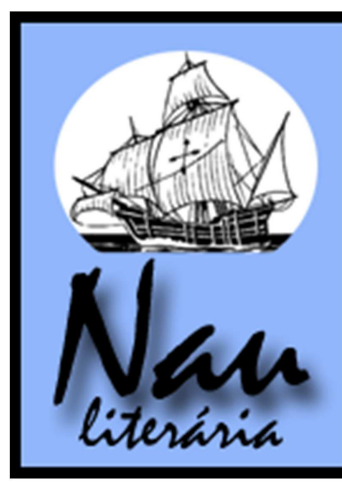

\title{
A escrita da leveza em Caim, de José Saramago
}

\section{Rodrigo Corrêa Martins Machado* Gerson Luiz Roani*}

\begin{abstract}
Resumo: José Saramago, com a publicação em 2009 do romance Caim, encerra um projeto de questionamento de um dos textos base da cultura ocidental, a Bíblia. Tal projeto havia sido iniciado em 1990 com a publicação do romance saramaguiano O Evangelho Segundo Jesus Cristo. No primeiro romance citado, vislumbra-se um embate entre o autor do Nobel português e o Novo Testamento bíblico, enquanto no segundo, o leitor depara-se com o questionamento do Antigo Testamento. Objetivamos no presente trabalho, analisar a desconstrução e questionamento do Antigo Testamento bíblico na obra saramaguiana Caim, tendo como base, principalmente o texto "Leveza" de Ítalo Calvino (1990). Recorreremos também à contribuição de teóricos como Linda Hutcheon (1991) e Mikhail Bakhtin (1987).
\end{abstract}

Palavras-Chave: José Saramago; Caim questionamento; Leveza.

\begin{abstract}
José Saramago, in 2009 with the publication of the novel Caim, finishes a project of questioning of one in the basic text of western culture, the Bible. This project had been initiated in 1990 with the publication of the novel Evangelho Segundo Jesus Cristo. In the first novel mentioned It is observed a clash between the Nobel Prize and the New Testament in the Bible, while in the second, the reader is confronted with the Ancient Testament. Considering the previous informations, we aim to analyze the deconstruction and questioning of the Old Testament in the Bible in the novel Caim (2009), based mainly text "Leveza" by Ítalo Calvino (1990). We refer also to the contribution of theorists such as Linda Hutcheon (1991) and Mikhail Bakhtin (1987).
\end{abstract}

Keywords: José Saramago; Caim; questioning; Lightness.

O mundo com seu pesadume, opacidade, petrificação das regras e dos valores, nos quais as sociedades se baseiam para organizarem-se, fez com que José Saramago, de certa forma, se rebelasse. Isto é, a partir de um olhar crítico acerca do mundo, como também das regras que o regem, Saramago notou que alguns discursos eram passíveis de desconstrução.

Desta forma, percebemos que José Saramago aderiu à premissa romântica de que fazer Arte significa transfigurar um objeto em função dos valores subjetivos do eu, o que é observado nas obras de caráter metaficcional historiográfico escritas por ele. Isso proporcionou a este artista da palavra interpelar aqueles valores que lhe foram impostos e com os quais não concordava. Dentre os discursos e valores com os quais Saramago discordava,

\footnotetext{
* Mestrando em Letras, com ênfase em Estudos Literários, pela Universidade Federal de Viçosa.

** Coordenador do Programa de Pós-Graduação em Letras e professor Adjunto da Universidade Federal de Viçosa. Doutor em Literatura Comparada pela UFRGS.
} 
estavam àqueles relacionados à Igreja, mais especificamente, com o livro utilizado há tantos anos pela Igreja para difusão de seus ideais, a Bíblia.

O questionamento bíblico por parte do romancista português em questão teve início em 1991 com o lançamento da obra Evangelho Segundo Jesus Cristo, através da qual o autor revisitou criticamente grande parte da narrativa bíblica concernente ao período de nascimento e morte do grande mártir da cristandade, Jesus Cristo. Digamos que o lançamento dessa obra e sua repercussão foram altamente polêmicos, mas por quê?

Isso se deu, principalmente, porque, em sua narrativa, José Saramago propôs-se a discutir e questionar um dos discursos humanos mais engessados, que é o discurso bíblico.

O ser humano prescinde de uma entidade superior para regular seus modos de viver e agir em sociedade, para tanto, desde a Grécia Antiga, entidades divinas foram criadas a fim de explicarem o inexplicável, de criar uma unidade de regras a serem seguidas socialmente. Os livros que compõem o Novo Evangelho Bíblico, e são seguidos ceticamente por muitos que se declaram cristãos, vieram à luz após a vivência terrestre de um homem chamado Jesus Cristo, um sujeito que através de suas ações humanitárias questionou as leis e os discursos petrificados que pregavam a segregação entre os homens.

Os homens criaram explicações e histórias para elucidarem a existência de Cristo, as quais são, após dois mil anos da possível existência cristã, são louvadas e adoradas por aqueles que seguem a filosofia de vida pregada por Jesus Cristo. Esse fato aponta que, para muitos humanos, o questionamento dessa figura divina é impossível, impensável e só poderia ser feito por alguém que habilmente observasse as lacunas existentes na Bíblia, concernentes à vida e ações de Cristo. Saramago o fez e isso levou a um desentendimento por parte da população cristã de seu país de origem, Portugal.

Em um romance mais recente, Caim (2009), José Saramago parece ter preterido continuar seu projeto de desconstrução e discussão da matéria bíblica. Como já havia feito isso em relação ao Novo Testamento cristão, dá continuidade ao seu projeto questionando e desconstruindo o Antigo Testamento judaico-cristão, principalmente no tocante à criação do Jardim do Éden, como também do ser humano.

Ao apresentar o mito de Perseu e do corte da cabeça da Medusa, Ítalo Calvino (1990, p. 16), apresenta-nos que, para decepar a cabeça do monstro Medusa, Perseu sustentou-se sobre as nuvens e o vento e, como não podia olhar diretamente para tal ser monstruoso, com risco de tornar-se algo petrificado, o herói lança um olhar indireto, através do espelho e depois corta-lhe a cabeça. Após essa exposição, o próprio Calvino sugere que encontra nesse mito "uma alegoria da relação do poeta com mundo". 
Para encontrarmos tal relação, devemos inicialmente, pensar em Medusa como um ser que petrifica, torna todos homogêneos, feitos da mesma matéria, incapazes de se movimentar, de questionar. Esse ser só foi destruído por outro que possuía certa leveza, uma vez que este sustentou-se sobre as nuvens e o vento, além de ser extremamente observador dos detalhes para perceber que, através da reflexão da imagem de Medusa, poderia destruí-la.

Isso nos leva a algumas associações para a observância desse mito como uma alegoria do poeta com o mundo. Primeiramente, devemos pensar no poeta, enquanto escritor, como um ser que busca apreender a substância imaterial, pura e complexa existente no mundo, que é a poesia. Somente a partir de sua captação e da transposição para o universo das palavras que a obra poderá ser realizada. Em segundo lugar, o que os não literatos vislumbram nada mais é do que o discurso duro, engessado, corriqueiro, diferenciando-os do poeta, uma vez que este possui uma capacidade de observância muito mais aprofundada do mundo físico e social que o circunda.

O poeta consegue tornar temas pouco leves "como sofrimento amoroso [...] em entidades impalpáveis, que se deslocam entre a alma sensitiva e alma intelectiva, entre coração e mente, entre os olhos e a voz" (CALVINO, 1990, p. 24). O poeta dissolve o sofrimento tanto na alma sensitiva quanto na intelectiva. Vale resssaltar que, muitas vezes, este sujeito constrói uma realidade outra, totalmente distinta de que vive, com sentimentos outros com os quais não se identifica, ele habilmente edifica um novo mundo a partir do seu. Destacamos a ocorrência desta criação de um outro mundo muito mais perceptivo e intelectivo no poema "Isto" de Fernando Pessoa:

$$
\begin{aligned}
& \text { Dizem que finjo ou minto } \\
& \text { Tudo o que escrevo. Não. } \\
& \text { Eu simplesmente sinto } \\
& \text { Com a imaginação. } \\
& \text { Não uso o coração. } \\
& \text { [...] } \\
& \text { Por isso escrevo em meio } \\
& \text { Do que não está ao pé } \\
& \text { Livre do meu enleio, } \\
& \text { Sério do que não é. } \\
& \text { Sentir? Sinta quem lê! } \\
& \text { (PESSOA, 2007, p. 165) }
\end{aligned}
$$

O poema "Isto" é conhecido como uma resposta pessoana quanto a uma crítica recebida que o acusava de fingidor e, portanto, mentiroso em seus escritos. Ao dizer que "Não. Eu simplesmente sinto com a imaginação", Pessoa postula que ao escrever ele não está mentindo, que seu sentimento provém da imaginação e que somente pensa em determinadas 
situações que não viveu ou que não pode viver em detrimento de outras e busca através do pensamento senti-las. O pensamento já é o bastante para que ele possa viver todas as situações que desejar.

Ao dizer que escreve "em meio do que está ao pé", revela-nos que escreve através de coisas, de sentimentos que não se pode alcançar facilmente, essas coisas que não estão ao pé são os próprios pensamentos, a própria poesia do autor que é desprovida de pensamentos e de sensações pelas quais ele já tenha passado. O poeta se concentra num mundo totalmente intelectualizado, quase impossível de ser alcançado.

Quando expressa "Sentir? Sinta quem lê!", podemos notar que o autor está a dar a resposta, de forma irônica, em relação ao primeiro parágrafo em que diz: "Dizem que finjo ou minto tudo o que escrevo". Para ele - enquanto um literato -, pouco importa a expressão do sentimento através da escrita, já que seu objetivo é fazer com que o leitor/apreciador do poema apreenda a mensagem que lhe é transmitida. Este é o único que poderá experimentar o texto, mesmo que a finalidade da matéria textual não seja a de ser sentida.

Desta maneira, o poeta deve ser como Perseu, ou seja, desviar seu olhar das coisas petrificadas e hipoteticamente inalteráveis e através da argúcia, da leveza encontrar caminhos desconhecidos para tornar o seu escrito digno de apreciação. Percebemos que, na construção de Caim, Saramago busca na Bíblia lacunas que os demais seres humanos não haviam observado até então. Ele conhece o discurso duro, engessado, difundido, principalmente, pelas religiões judaico-cristãs, que para muitos seria impassível de desconstrução, e buscou encontrar, através da agilidade, sutileza, leveza de pensamento, elementos, caminhos ainda não explorados.

Como Calvino (1990, p. 17), apresenta-nos "Do sangue da Medusa nasce um cavalo alado, Pégaso; o peso da pedra pode reverter em seu contrário [...]", a partir do discurso petrificado pode surgir uma nova matéria distinta e que questione, ou melhor, que reverta esse peso em uma espécie de leveza. Isso também não difere da escrita saramaguiana em questão, uma vez que a partir do discurso bíblico engessado, o autor consegue transfigurá-lo em um Outro.

O principal mecanismo utilizado por Saramago para alcançar o almejado é a paródia. Através do recurso paródico, o autor faz com que os intertextos bíblicos sejam vistos como uma reelaboração, para que nasça uma nova visão do "mundo" de maneira mais distanciada e, talvez por isso, mais crítica. O autor, ao parodiar, não deseja destruir os vestígios ou o que se conhece sobre o tempo pretérito, "na verdade, parodiar é sacralizar o passado e questioná-lo ao mesmo tempo" (HUTCHEON, 1991, p. 165), ao contrario, ao parodiar o texto bíblico e 
também histórico selecionou uma escritura com que se pode dialogar, a fim de deixá-la marcada como importante, sacralizando-a sacralizou e questionando-a ao mesmo tempo. Além disso, ele discutiu e discute as possíveis verdades suprimidas da Bíblia, que são necessárias para que se reflita acerca dos discursos de poder que são veiculados pelas instituições caracteristicamente dominadoras, como a Igreja e o Estado.

Assim, a paródia é importante para a constituição textual, na medida em que possibilita a abertura narrativa - abertura a discussão, a questionamentos, rediscussões, novas interpretações de textos e elementos neles presentes. O fechamento do texto não é mais aceito, não se acredita mais que uma verdade possa ser inverificável, inquestionável.

Uma discussão que deve ser inegavelmente levada em consideração, diz respeito ao fato de que a paródia funciona também como uma forma de se proporcionar à História e aos fatos uma nova possibilidade de discussão.

"É sempre na recusa da visão direta que reside a força de Perseu, mas não na recusa da realidade do mundo de monstros entre os quais estava destinado a viver, uma realidade que ele traz consigo e assume como fardo pessoal" (CALVINO, 1990, p. 17). Da mesma forma ocorre com Saramago, já que ao recusar a "Verdade" das instituições religiosas e da própria Bíblia, ele atinge seu objetivo. Ele não nega a existência da matéria bíblica, mas coloca-a em discussão direta, torna-a algo aberto e passível de ser desconstruído. A partir do monstruoso, do estanque, o poeta consegue libertar algo divino, pode proporcionar às pessoas uma visão distinta da existente.

"No universo infinito da literatura sempre se abrem outros caminhos a explorar, novíssimos ou bem antigos, estilos e formas que podem mudar nossa imagem do mundo..." (CALVINO, 1990, p. 20). A escrita presente em Caim, através do diálogo entre o antigo com o novo, a partir da revisitação do passado com um olhar extremamente contemporâneo, expande as fronteiras textuais tanto da Bíblia, quanto do romance em questão. O escritor romanesco demonstra como é tênue a fronteira textual e como ela é passível de desconstrução e isso é feito através da intertextualidade.

No que diz respeito à intertextualidade, é senso comum falarmos que todos os textos produzidos hoje possuem algum diálogo com outros criados anteriormente, "uma obra literária já não pode ser considerada original; se o fosse, não poderia ter sentido para seu leitor. [...] é apenas como parte de discursos anteriores que qualquer texto obtém sentido e importância" (HUTCHEON, 1991, p. 169).

Um autor, ao escrever, acaba por imprimir em sua obra pontos-de-vista e ideias retiradas de textos estudados anteriormente. Linda Hutcheon (1991, p. 166), ao abordar este 
assunto, explicita que "esse vínculo formal por intermédio dos denominadores comuns da intertextualidade e da narratividade costuma ser apresentado não como uma redução ou como encurtamento do âmbito e do valor da ficção, mas sim como uma ampliação”.

Em qualquer escrito, o autor transpõe para os textos suas ideologias, ideias, preferências, leituras e seus intertextos literários. A partir do diálogo com o texto bíblico, José Saramago empreende uma ousada meta: criar uma nova história para tal texto, visando questionar o mito da criação do Jardim do Éden e da invenção do ser humano por Deus, os desconstruindo.

A intertextualidade é importante não só para o autor, ao escrever seus romances, mas também para o leitor, uma vez que a este é destinado à obra literária. Linda Hutcheon (1991, p. 167) ao tratar da intertextualidade afirma:

Sua utilidade como uma estrutura teórica (...) é óbvia ao se lidar com a metaficção historiográfica, que exige do leitor não apenas o reconhecimento de vestígios textualizados do passado literário e histórico, mas também a percepção daquilo que foi feito- por intermédio da ironia- a esses vestígios. O leitor é obrigado a reconhecer não apenas a inevitável textualidade de nosso conhecimento sobre o passado, mas também o valor e a limitação da forma inevitavelmente discursiva desse conhecimento.

José Saramago está evitando que sejamos esmagados pelo peso da matéria, que a tomemos como verdade única, universal e excludente em relação a quaisquer outras visões. Através da escrita saramaguiana, observamos que o autor compartilha das ideias de Ovídio, para o qual "tudo pode assumir formas novas" e "o conhecimento do mundo é a dissolução de sua compacidade" (CALVINO, 1990, p. 21). O próprio ato de questionar já se afigura como a não aceitação das formas fixas; assinala uma nova forma a surgir, primeiramente, na cabeça do poeta e, para este artista conhecer o mundo ele sempre busca dissolver as partes homogeneizadas, petrificadas.

A partir da substância comum, como é o caso das histórias da Criação do Jardim do Éden e do surgimento do ser Humano, Saramago cria algo novo, irreverente. Ele utiliza a palavra engessada para, através dela, construir outra visão de mundo. É a partir da leveza do pensamento saramaguiano que aquilo que o corriqueiro, o institucionalizado enquanto inquestionável, transforma-se em algo completamente novo e, por muitos, impensável.

$\mathrm{O}$ autor de Caim reitera a premissa calviniana de que "[...] não podemos admirar a leveza da linguagem se não soubermos admirar igualmente a linguagem dotada de peso" (CALVINO, 1990, p.27). Uma vez que, somente a partir do conhecimento fundado na pesquisa, no estudo a fundo da linguagem utilizada no discurso petrificado, Saramago se 
propõe a questioná-la e criar uma nova linguagem, uma visão mais leve e destituída de "verdade".

Muitas das obras escritas por Saramago se imporão à memória não por criarem um novo mundo com regras a serem seguidas, mas devido à sugestão verbal que as palavras terão. Elas são e serão os verdadeiros responsáveis pela libertação, pela criação de uma nova possibilidade de constituição verbal que ainda aponta para muitas outras que poderão surgir ao longo dos anos. É exatamente a sutileza na utilização da linguagem que a tornará tão libertadora e distinta das formas produzidas com fins de domínio social.

Existe o que Calvino chama de "modulação lírica e existencial" no tratamento do assunto pelo autor, “ que permite contemplar o próprio drama como se visto do exterior, e dissolvê-lo em melancólica ironia" (CALVINO, 1990, p. 32). Surge um discurso relacionado à melancolia e ao humor, que para Calvino "põe em dúvida o eu e o mundo, com toda a rede de relações que os constituem", como acontece em Caim, livro no qual o autor lança um olhar distanciado em relação à matéria tratada (mesmo que ela se faça presente na vida de grande parte das pessoas) e a dissolve em uma melancólica ironia, fazendo com que o seu leitor questione a si mesmo e ao mundo que ele conhecia até então. O livro permite ao seu leitor a oportunidade de repensar a si e toda a ideologia que perpassa sua sociedade.

Nesse novo discurso que nasceu do diálogo dessacralizador do presente em relação ao passado, o autor coloca todas as personagens em pé de igualdade. Como é o caso da relação entre Deus e Caim. No discurso bíblico, Deus é o ser maior, incomparável, inquestionável, já na narrativa saramaguiana Deus, apesar de todo o poder divino que possui, encontra-se em pé de igualdade com as demais personagens (uma aproximação ao nível discursivo) observável, inclusive, pela grafia de todos substantivos próprios com letra minúscula. Isso nada mais é do que a representação da carnavalização teorizada por Mikhail Bakhtin, que diz:

O carnaval ignora toda a distinção entre atores e espectadores. Também ignora o palco, mesmo
na sua forma embrionária. Pois o palco teria destruído o carnaval (e, inversamente, a destruição
do palco teria destruído o espetáculo teatral). Os espectadores não assistem ao carnaval, eles o
vivem, uma vez que o carnaval pela sua própria natureza existe para todo o povo. Enquanto
dura o carnaval não se conhece outra vida senão a do carnaval (BAKHTIN, 1987, p. 6).

Podemos relacionar a definição de carnaval bakhtiniana com o texto romanesco em questão, na medida em que observamos que, neste romance, Saramago abre seu texto a uma contínua discussão com as personagens e com os interlocutores. Todos têm voz e exprimem o que sentem - de acordo com Bakhtin temos um exemplo de discurso dialógico, polifônico. 
A polifonia imprime ao romance uma espécie de possibilidade de manifestação de grupos diferenciados, de épocas distintas, cada um vislumbrando a história bíblica de uma maneira peculiar e ao mesmo tempo universal.

A carnavalização é responsável pela derrogação das fronteiras temporais, espaciais, genealógicas e sociais, uma vez que no romance em questão o discurso repressor da Bíblia e o contexto contemporâneo, dotado de questionamentos, se cruzam de maneira incessante, nem mesmo as figuras, acontecimentos e outros elementos pertencentes à história deixam de ser atingidos.

Todo o discurso presente na obra é voltado para o outro, para as reflexões que poderão ser feitas a partir da leitura do romance. Para Bakhtin, essa orientação do discurso para o outro tem fundamentos sociais, o sujeito passa a se conhecer na terceira pessoa, passa a ver as coisas com um olhar mais distanciado, para poder julgar melhor a situação. Isso não quer dizer que seja um olhar neutro, muito pelo contrário, sabemos que não existe nenhum discurso neutro, e por isso, podemos afirmar que o discurso do autor quer nos fazer questionar toda uma História bíblica difundida há séculos.

A relação de destaque neste romance saramaguiano é a de Deus e Caim. Para a construção de tal relacionamento é inegável a utilização, por parte de Saramago, da carnavalização, além de muita ironia e paródia. Caim, por ser uma personagem de caráter irônico, estabelece com Deus uma relação caracteristicamente questionadora e crítica, o que, no romance, faz com que ele e Deus tenham uma relação extremamente conflituosa e desafiadora.

Para que possamos apresentar mais contundentemente ironia e paródia na relação entre estas duas personagens, devemos inicialmente retomar o texto bíblico, no qual, Caim, após matar Abel, é castigado por Deus, que o manda vagar por um tempo até se tornar o fundador da primeira cidade, Enoch. Os descendentes de Caim estabeleceram-se nesta cidade, criaram habilidades para a metalurgia, criação de gado e música, e, foram extintos pelo dilúvio (BÍBLIA, 2002).

Já em Caim, a personagem que dá nome a obra, desde o primeiro momento que se encontra com Deus, se mostra altamente crítica e questionadora, principalmente, dos poderes que essa divindade teria para controlar a tudo. Interessante notarmos que essa relação ocorre, de certa forma, em um patamar de igualdade, em que nenhuma das personagens se sente ou é apresentada como inferior a outra.

No decorrer da narrativa, Caim vive e vê os vários mandos e desmandos de Deus para com a humanidade, aponta injustiças que esta divindade comete, critica suas ações, discute 
diretamente com ele, enfim, possui um olhar muito mais crítico, ativo do que passivo em relação a este Deus, a esta figura paternal que tudo rege e em tudo manda.

No romance, uma das primeiras passagens que se refere à relação entre eles é um tanto quanto reveladora do ódio que o filho de adão nutria por Deus "Ao matar abel por não poder matar o senhor, caim deu já a sua resposta" (SARAMAGO, 2009, p. 37). O primeiro encontro entre eles se deu, então, após esta personagem matar seu irmão, que era o preferido de Deus entre os dois. Ao contrário da Bíblia, na qual todos se resignam à vontade de Deus, em Caim, a personagem que dá nome ao livro questiona e critica os mandos celestes:

Que fizeste com o teu irmão, perguntou [deus],e caim respondeu com outra pergunta, Era eu o guarda-costas de meu irmão, Mataste-o, Assim é, mas primeiro culpado és tu, eu daria a minha vida pela dele se tu não tivesses destruído a minha. Quis pôr-te a prova, E tu quem és para pores à prova o que tu mesmo criaste, Sou dono soberano de todas as coisas. E de todos os seres, dirás, mas não de mim nem da minha liberdade, Liberdade para matar, Como tu foste livre para deixar que eu matasse abel quando estava na tua mão evitá-lo, bastaria que por um momento abandonasse a soberba da infalibilidade que partilhas com todos os outros Deuses, bastaria que por um momento fosses realmente misericordioso [...] (SARAMAGO, 2009, p. 34)

Nesta passagem, Caim põe à prova a misericórdia divina, ironiza com o poder de Deus em controlar a vida humana e de certa maneira o desafia, ao dizer que sua liberdade a ninguém pertence, nem mesmo a uma divindade. A paródia que o narrador imprime ao texto bíblico já inicia o processo de desconstrução da "verdade" bíblica, lançando sobre ela a dúvida acerca do amor de Deus e até mesmo de sua existência.

Após este encontro entre Deus e Caim, esta personagem foi paródico e ironicamente mandada vagar pelo mundo, mas não como aparece na Bíblia para criar Enoch ou artes, e sim como um vagabundo eterno, que nada fundou. Através dela, Saramago revisitará variadas passagens bíblicas e as desconstruirá, a primeira é a de Abraão e Isaac, na qual Deus pediu àquele que provasse seu amor matando seu único filho. No romance, Abraão iria oferecer a vida de seu filho ao senhor, no entanto, Caim chegou a tempo de salvar a criança da morte e questiona a vontade divina ao dizer ao anjo que chegara atrasado para salvar Isaac: “[...] não compreendo como irão ser abençoados todos os povos do mundo só porque abraão obedeceu a uma ordem estúpida" (SARAMAGO, 2009, p. 81).

No capítulo 7 da obra, o filho de adão encontra-se novamente com Abraão, porém em um momento anterior até mesmo ao nascimento de Isaac, exatamente quando Deus faz o prenuncio de que Abraão e sara, na velhice, teriam um filho. O senhor também iria à Sodoma e Gomorra para destruir estas cidades, nas quais os homens preferiam outras pessoas do mesmo sexo às mulheres. Caim e Abraão, após saberem pelo senhor as notícias da destruição das cidades, iniciaram uma pequena discussão sobre Deus poupar os inocentes que residiam 
nestes locais e as maneiras como ele faria para encontrá-los. Após a discussão, ambos foram às cidades averiguar o que se passava. Nesta passagem, Caim novamente questionará as ações divinas, as ironizando, como veremos a seguir:

Tenho um pensamento que não me larga, Que pensamento, perguntou abraão, Penso que havia inocentes em Sodoma e nas outras cidades que foram queimadas, Se os houvesse, o senhor teria cumprido a promessa que me fez de lhes poupar a vida, As crianças, disse caim, aquelas crianças estavam inocentes, Meu deus, murmurou abraão e a sua voz foi como um gemido, Sim, será o teu deus, mas não foi o delas (SARAMAGO, 2009, p. 97).

Em pontos da narrativa, Caim dialoga com o interlocutor textual, deixando claro que não acreditava na bondade e misericórdia divinas, principalmente no tocante às guerras empreendidas em nome e pelo senhor, e também em provações que Deus colocou os seres humanos para provar o amor destes por ele. Algumas passagens exemplificam claramente este dialogo entre Caim e os interlocutores:

Eu não fiz mais que matar um irmão e o senhor castigou-me, quero ver agora quem vai castigar o senhor por estas mortes, pensou caim, e logo continuou, Lúcifer sabia bem o que fazia quando se rebelou contra deus, há quem diga que o fez por inveja e não é certo, o que ele conhecia era a maligna natureza do sujeito (SARAMAGO, 2009, p. 101)

Quando chegou até a família de noé, Caim se encontrou novamente com Deus. Este encontro, como os anteriores, não foi pacífico. O filho de adão não só apontou todas desgraças causadas pelo senhor, como também interrogou até que ponto este Deus era pleno de bondade e amor pelos homens:

[deus] Que fazes por aqui, nunca mais te vi desde o dia em que matastes o teu irmão, Enganaste, senhor, vimo-nos, embora não me tenhas reconhecido, em casa de abraão, nas azinheiras de mambré, quando ias destruir sodoma, Foi um bom trabalho, esse, limpo e eficaz, sobretudo definitivo, Não há nada de definitivo no mundo que criaste, job julgava estar a salvo de todas as desgraças, mas a tua aposta com satã reduziu-o à miséria e o seu corpo é uma pegada chaga, assim o vi quando saí da terra de us, Já não, caim, já não, a pele dele sarou completamente e os rebanhos que tinha duplicaram, agora tem catorze mil ovelhas, seis mil camelos, mil juntas de bois e mil jumentos, E como conseguiu ele,, Dobrou-se à minha autoridade, reconheceu que meu poder é ilimitado, que não tenho que dar contas senão a mim mesmo nem me deter por considerações de ordem pessoal, isto digo-to agora, sou dotado de uma consciência tão flexível que sempre a encontro de acordo com o que quer que eu faça, [...] (SARAMAGO, 2009, p. 149).

O desafiar de Caim a Deus pode ser observado também a seguir: "Admites então que haja no universo uma outra força, diferente e mais poderosa que a tua, é possível, não tenho por hábito discutir transcendências ociosas [...] (SARAMAGO, 2009, p. 150).

Observamos, até o presente momento, que Caim está convencido e, juntamente com o narrador, induz o interlocutor textual a perceber que Deus criou o mundo, os homens, os seres em geral, apenas para se distrair do ostracismo divino. Ele dotou os homens de vida, 
inteligência, entretanto, busca a todo o momento controlá-los, manipulá-los, se lhes desagradam, Deus simplesmente os destrói e inicia a "brincadeira" com outros. O Senhor tem prazer em ver os homens lutando, morrendo, sofrendo para the provar o amor que por ele possuem. Porém, Caim, enquanto alguém que criou um embate de ódio contra o senhor, em sua mísera humanidade, deseja acabar com as atrocidades cometidas pela divindade.

No momento em que embarca com Noé e família na arca, Caim se vê dotado de poderes para destruir os planos divinos, que seriam destruir a humanidade e reconstruí-la novamente. Para embater com Deus e ir contra os planos deste, a personagem que dá nome à obra mata todos os seres humanos da arca de Noé (exceto Noé que se suicida após perceber os fracassos de sua viagem), para que não houvesse mais a construção de outra humanidade, que antes mesmo de nascer estaria fadada à desgraça e aos desmandos do senhor.

Ao final do romance há o último e talvez o mais importante encontro entre Caim e Deus. Nesta passagem, o senhor chama a Noé e família para saírem da arca e se depara somente com o filho de adão, que diz que Noé e família estavam mortos. O senhor se espanta e diz a Caim: "Como te atreveste, assassino, a contrariar o meu projecto, é assim que me agradeces por ter-te poupado a vida quando mataste abel, perguntou o senhor" (SARAMAGO,2009, p. 172). Neste momento, Caim expõe à divindade suprema todos os sentimentos que estavam resguardados em seu interior, principalmente, os que dizem respeito às atrocidades cometidas por Deus e vivenciados, de alguma forma, pela que dá nome ao romance:

Teria de chegar o dia em que alguém te colocaria perante a tua verdadeira face, Então a nova humanidade que eu tinha anunciado, Houve uma, não haverá outra e ninguém dará pela falta, caim és, e malvado, matador do teu próprio irmão, Não tão malvado e infame como tu, lembraste das crianças de sodoma. Houve um grande silêncio. Depois Caim disse, Agora já podes matar-me, Não posso, palavra de deus não volta atrás, morrerás da tua natural morte na terra abandonada e as aves de rapina virão devorar-te a carne, Sim, depois de tu primeiro me haveres devorado o espírito. (SARAMAGO, 2009, p. 172)

Percebemos, através da análise empreendida do romance saramaguiano Caim, a utilização da escrita com vistas a mudar algo, de transformar não somente uma história conhecida por todos os povos, mas de mostrar às pessoas o quanto é ela é passível de desconstrução, além do fato de apontar para que não tenhamos que nos curvar à história que nos é imposta. Pelo contrário, não só podemos, como devemos questioná-la a fundo. Entendemos a palavra como Calvino (1990, p. 39) destaca, “[...] do uso da palavra como a entendo, ou seja, como perseguição incessante das coisas, adequação à sua infinita variedade". 
Através do discurso engessado, petrificado, Saramago cria uma história em constante diálogo com a imposta até então. Ele torna algo extremamente pesado em leve, em passível de desconstrução. A palavra é o meio pelo qual se pode questionar a própria palavra e construir um mundo mais igualitário, por exemplo, aproximando um homem de um Deus.

Se a linguagem em si é algo que possui uma grande infinidade, os discursos que dela podem surgir também são muitos, o que nos permite construir, a partir de um único texto, muitas versões ou formas distintas. Criar um sentido novo não é fácil, para isso acontecer, devemos ir ao nível do Outro em busca de forças capazes de mudar a realidade, necessitamos de não somente questionar algo, mas antes de tudo conhecê-lo a fundo para que possamos fazer isso habilmente. Cada vez que discordamos de algo e tentamos modificá-lo voamos a outro mundo, porque estamos leves, em fuga da repressão cotidiana que nos espreita em cada esquina.

\section{Referências}

BAKHTIN, M. M. Problemas da poética de Dostoiévski. Tradução de Paulo Bezerra. Rio de Janeiro: Forense Universitária, 1981.

BÍBLIA. Português. Bíblia sagrada. Tradução de Damião de Góis. Lisboa: Fundação Calouste Gulbenkian, Serviço de Educação e bolsas, 2002.

CALVINO, Ítalo. Leveza. In: Seis Propostas para o Próximo Milênio. $2^{\mathrm{a}}$ ed. Tradução de Ivo Barroso. São Paulo: Companhia das Letras, 1990, pp. 13 - 42.

HUTCHEON, Linda. Poética do pós-modernismo: história, teoria, ficção. Tradução de Ricardo Cruz. Rio de Janeiro: Imago Ed, 1991.

PESSOA, Fernando. Obra poética. $3^{\mathrm{a}}$ ed. Rio de Janeiro: Nova Fronteira, 2007.

SARAMAGO, José. O Evangelho Segundo Jesus Cristo. São Paulo: Companhia das Letras, 1991. Caim. São Paulo: Companhia das Letras, 2009. 